\title{
The tumour suppressor SOX11 is associated with improved survival among high grade epithelial ovarian cancers and is regulated by reversible promoter methylation
}

Sandra Sernbo 1,2, Elin Gustavsson ${ }^{1,2}$, Donal J Brennan ${ }^{3}$, William M Gallagher ${ }^{3}$, Elton Rexhepaj ${ }^{3}$, Frida Rydnert ${ }^{1,2}$, Karin Jirström ${ }^{4}$, Carl AK Borrebaeck ${ }^{1,2}$ and Sara Ek ${ }^{1,2^{*}}$

\begin{abstract}
Background: The neural transcription factor SOX11 has been described as a prognostic marker in epithelial ovarian cancers (EOC), however its role in individual histological subtypes and tumour grade requires further clarification. Furthermore, methylation-dependent silencing of SOX11 has been reported for B cell lymphomas and indicates that epigenetic drugs may be used to re-express this tumour suppressor, but information on SOX11 promoter methylation in EOC is still lacking.

Methods: SOX11 expression and clinicopathological data was compared using $\chi^{2}$ test in a cohort of 154 cases of primary invasive EOC. Kaplan-Meier analysis and the log rank test were applied to evaluate ovarian cancer-specific survival (OCSS) and overall survival (OS) in strata, according to SOX11 expression. Also, the methylation status of the SOX11 promoter was determined by sodium bisulfite sequencing and methylation specific PCR (MSP). Furthermore, the effect of ectopic overexpression of SOX11 on proliferation was studied through [3H]-thymidine incorporation.

Results: SOX11 expression was associated with an improved survival of patients with high grade EOC, although not independent of stage. Further analyses of EOC cell lines showed that SOX11 mRNA and protein were expressed in two of five cell lines, correlating with promoter methylation status. Demethylation was successfully performed using 5'-Aza-2'deoxycytidine (5-Aza- $\mathrm{dC}$ ) resulting in SOX11 mRNA and protein expression in a previously negative EOC cell line. Furthermore, overexpression of SOX11 in EOC cell lines confirmed the growth regulatory role of SOX11.
\end{abstract}

Conclusions: SOX11 is a functionally associated protein in EOC with prognostic value for high-grade tumours. Reexpression of SOX11 in EOC indicates a potential use of epigenetic drugs to affect cellular growth in SOX11-

negative tumours.

Keywords: SOX11, EOC, DNA methylation, epigenetic regulation

\section{Background}

EOC is a heterogeneous disease compromising many histological subtypes including clear cell, mucinous, endometrioid and serous carcinoma, which are subclassified into high- and low-grade [1]. Differences in survival between the histological subtypes have been observed, with mucinous and endometrioid carcinomas having a more favourable prognosis compared to high

\footnotetext{
* Correspondence: Sara.Ek@immun.lth.se

'Department of Immunotechnology, Lund University, Lund, Sweden Full list of author information is available at the end of the article
}

grade serous [2] and clear cell carcinomas [3], most likely related to distinct differences in tumour biology [4]. It has been emphasized that each EOC subtype needs to be considered separately in order to identify clinically relevant biomarkers [5]. EOC, and the clear cell subtype in particular, is known to only initially be responsive to chemotherapy treatment [6] and the main prognostic factor remains surgical debulking status $[7,8]$. This emphasizes that targeted therapies, potentially specific for each subtype, are needed in combination with improved methods for early detection. To identify the biology underlying 
each clinical subtype and develop new therapeutic targets, gene expression profiling has been used $[9,10]$. Among others, a new subtype of high grade serous cancer reflecting a mesenchymal cell type, characterized by low expression of MUC1, has been identified. This new subgroup has an undifferentiated phenotype and expresses developmentally associated transcription factors, including SOX11, as well as other high-mobility group members such as HMGA2, TOX and TCF7L1 [11].

SOX11 is a diagnostic and prognostic antigen in B cell lymphomas [12-17] and has recently been demonstrated by us to have tumour suppressor functions [18]. This transcription factor is also a prognostic antigen in EOC, where its presence is associated with improved recurrence-free survival (RFS) [19]. In the present study, we confirm the relationship between SOX11 and survival in EOC, although a larger set of endometrioid cancer needs to be investigated to show independent prognostic relevance. To identify suitable in vitro models for functional analyses, EOC cell lines were screened for SOX11 expression and promoter methylation was assessed in both positive and negative cell lines. To verify that methylation is a key event in silencing SOX11, 5-Aza-dC treatment was used to re-express SOX11 in an in vitro model of EOC. Furthermore, the tumour suppressor function of SOX11, as previously reported for B cell lymphomas [18], was now extended to EOC and demonstrated through transient over-expression of SOX11.

In summary, we show that SOX11 is a prognostic and functional antigen associated with improved survival in high grade EOC. Furthermore, specific promoter methylation was shown to be a key event in silencing SOX11.

\section{Methods}

\section{Clinical material and construction of tissue microarrays}

The tissue microarray (TMA) was constructed from a consecutive cohort of 154 cases of primary invasive EOC from the prospective, population based cohorts Malmö Diet and Cancer [20] and Malmö Preventive Medicine [21]. The histological re-evaluation of the joint cohort and construction of the TMA has previously been described by Ehlén et al. [22]. The patient cohort is summarised in Table 1. All national and international guidelines including the Helsinki Declaration on ethical principles for medical research involving human subjects, i.e. Declaration of Helsinki - Ethical Principles for Medical Research Involving Human Subjects (2000) were applied during the project.

\section{Immunohistochemical analysis of SOX11}

TMA sections were pre-treated as previously described [19]. Immunohistochemistry (IHC) was performed, using the primary rabbit anti-human SOX $11^{\mathrm{C} \text {-term }}$ antibody
Table 1 Clinicopathological characteristics in the total cohort and the SOX11 positive subgroup

\begin{tabular}{lll}
\hline Histology & $\mathbf{N}$ total $(\%)^{\mathbf{1}}$ & N SOX11 positive $(\%)^{\mathbf{2}}$ \\
\hline Total & 154 & 55
\end{tabular}

Histological subtype

Mucinous

Serous

$12(8)^{1}$

$90(58)$

$3(5)$

Endometrioid

Clear cell

$35(23)$

$31(56)$

Clear cel

9 (6)

Brenner

$1(0.6)$

$17(31)$

Unknown

$7(5)$

$4(7)$

$\begin{array}{lll}\text { Grade } & & \\ \text { High }^{3} & 107(70) & 40(73) \\ \text { Low }^{4} & 47(30) & 15(27)\end{array}$

Stage

I $26(17) \quad 10(18)$

| $\quad 18(12) \quad 9(16)$

III $\quad 75(49) \quad 26(47)$

IV $\quad 22(14) \quad 5(9)$

Unknown $13(8) \quad 5(9)$

${ }^{1}$ The percentage is based on the total number of cases.

${ }^{2}$ The percentage is based on the total number of SOX11 positive cases.

${ }^{3}$ High grade includes cases with low differentiation grade

${ }^{4}$ Low grade includes cases with intermediate and high differentiation grade.

[13], according to a previous staining protocol [19]. Briefly, signal was detected, using the Dako REAL Detection system and slides were counterstained with Mayers hematoxylin (Sigma-Aldrich, St Louis, MO).

Image Acquisition, Management and Automated analysis and statistical analysis

The Aperio ScanScope XT Slide Scanner (Aperio Technologies, Vista, CA) system was used to capture whole slide digital images with a $20 \mathrm{X}$ objective and nuclear SOX11 expression was automatically quantified. A tumor specific nuclear algorithm (IHC-MARK) was developed in house to quantify SOX11 protein expression. IHC-MARK was designed to identify tumor cells on the basis on nuclear morphology and disregard non-tumor cells such as normal epithelial or stromal cells, or invading leukocytes as previously described [23]. The algorithm calculated the percentage of positive tumor cells, as well as relative staining intensity ranging from 0 to 255 . Patients were divided into subgroups having either higher or lower than 10\% nuclear SOX11 expression. Statistical analysis was performed, as previously described [19]. Briefly, the $\chi^{2}$ test was used for comparison of SOX11 expression and clinicopathological data, and Kaplan-Meier analysis and the log rank test were applied to evaluate and illustrate ovarian cancer specific survival (OCSS) and overall 
survival (OS) in strata, according to SOX11 expression. Cox regression proportional hazards models were used to estimate the relationship between SOX11 expression in high grade tumours and stage. All calculations were performed, using SPSS version 11.0 (SPSS Inc, Chicago, IL).

\section{Cultivation of EOC cell lines}

In total, five different EOC cell lines (Table 2) were used in the study: TOV-112D, derived from malignant solid epithelial ovarian tumour specimens [24], NIH:OVCAR-3, originating from the malignant ascites of a patient with progressive adenocarcinoma [25], ES-2 [26], A2780 and A2780-CP7 [27]. The cell line TOV-112D was cultured in DMEM High Glucose media (Hyclone, South Logan, Utah, USA) supplemented with 15\% fetal bovine serum (FBS) and 1\% L-glutamin (both Invitrogen, Carlsbad, CA, USA). OVCAR-3 was maintained in RPMI-1640 media (HyClone) supplemented with 20\% FBS, 1\% L-glutamin and $0,01 \mathrm{mg} / \mathrm{ml}$ insulin (Sigma-Aldrich). A2780 and A2780-CP7 were maintained in RPMI-1640 media supplemented with 10\% FBS and 1\% $200 \mathrm{mM}$ L-glutamine. ES-2 was cultured in McCoy's 5A media (HyClone) supplemented with $10 \%$ FBS.

\section{RNA isolation and quantitative real time PCR}

The relative quantity (RQ) of SOX11 mRNA in various cell lines was identified using Real Time-quantitative PCR (qRT-PCR). The cells were lysed and cDNA synthesis performed using the Fast SYBR Green Cells-to-CT kit and the samples were run on a Fast 7500 qRT-PCR system (Applied Biosystems, Foster City, CA, USA), as previously described [18]. Briefly, 30 000-50 000 cells were washed in PBS, lysed and treated with DNase. Lysates were reversedtranscribed and cDNA amplified in three technical replicates with the following primer specific either for SOX11 or the house-keeping gene GAPDH (the concentration was 250 nM (MWG, High-Point, NC, USA)); GAPDH: 5'TGGTATCGTGGAAGGACTC-3' and 5'-AGTAGAGGCAGGGATGATG-3', SOX11: 5'-GGTGGATAAGGATTTGGATTCG-3' and 5'-GCTCCGGCGTGCAGT AGT-3'. The RQ is calculated as $2^{-(\triangle \Delta C T(S O X 11-G A P D H))}$. For analysis of absolute levels of SOX11, a control sample

\section{Table 2 EOC Cell line characteristics}

\begin{tabular}{ll}
\hline Cell line & Disease \\
\hline TOV-112D $^{1}$ & Primary malignant adenocarcinoma \\
OVCAR-3 $^{3}$ & Progressive adenocarcinoma \\
ES- $^{1}$ & Poorly differentiated ovarian clear cell carcinoma \\
A2780 $^{2}$ & Undifferentiated CA \\
A2780-CP7 & Undifferentiated CA
\end{tabular}

1 - Kindly provided by Gabriella Honeth, Department of oncology, Lund University.

2 - Kindly provided by who Prof R Brown, Imperial College, London.

3 - American Type Culture Collection (ATCC). was run, containing lysate but no reverse transcriptase (RT), enabling estimation of amplification above genomic level, as previously described [18]. Generally, all samples with a $\Delta \mathrm{C}_{\mathrm{T}}(\mathrm{SOX} 11+\mathrm{RT}$, SOX11-RT) $<|2|$, here after referred to as $\Delta \mathrm{C}_{\mathrm{T}, \mathrm{SOX} 11 \text {, were considered negative. All the error bars }}$ related to qRT-PCR data have been calculated using the standard error (SE) value with a $95 \%$ confidence interval.

\section{Protein purification and quantification}

Protein was extracted and quantified as previously described [18]. Briefly, 0.2 to 8 million cells were harvested, washed and placed in $200 \mu \mathrm{l}$ lysis-buffer (1\% Ipegal/Protease Inhibitor cocktail (Roche, Basel, Switzerland) in PBS).

\section{Western Blot analysis of SOX11-knockdown and differential expression}

Protein lysates, $43 \mu \mathrm{g}$ for wild-type expression, lysates of 0.2 million cells for demethylation and $30 \mu \mathrm{g}$ for overexpression, from five ovarian cancer cell lines were run on NuPAGE 10\% Bis-Tris gels (Invitrogen, Carlsbad, CA, USA) under reducing conditions for $\sim 45 \mathrm{~min}$ at $130 \mathrm{~V}$. Separated proteins were blotted on PVDF iBlot Transfer stacks in the iBlot gel transfer device (both Invitrogen) and blocked for $1 \mathrm{~h}$. SOX11 protein expression was verified using an antibody targeting SOX11 (Atlas Antibodies, Stockholm Sweden) and a HRP-labelled swine anti-rabbit antibody (DAKO, Glostrup, Denmark) as secondary antibody. Blots were developed, using the SuperSignal West Femto Maximum Sensitivity Substrate (Pierce, Thermo Scientific, Waltham, MA, USA), according to the protocol of the manufacturer, detected in a CCD-camera and analysed in the Quantity One software (both Bio-Rad, Hercules, CA, USA).

\section{Analysis of promoter methylation status}

The methylation status of the SOX11 promoter was determined by sodium bisulfite sequencing and MSP. Briefly, DNA was extracted from the cell lines with QIAamp DNA Mini Kit (QIAgen, Hilden, Germany). 0.5$1 \mu \mathrm{g}$ of DNA was bisulfite converted with QIAgen Epitect Bisulfite Kit (QIAgen) and 50-100 ng of converted DNA was used as template in the PCR. Epitect Control DNA (QIAgen) was used as controls in all PCR reactions to ensure specific PCR amplification using Platinum Taq DNA polymerase (Invitrogen). For bisulfite sequencing, primers that amplified a 213 bp region containing 28 CpG's adjacent to the 5' end of the SOX11 transcription start site were used as previously described [18]. PCR products were directly sequenced by Eurofins MWG Operon (Ebersberg, Germany). Clonal analysis of individual alleles was made by subcloning the PCR fragments into pCR.21-TOPO vector (Invitrogen) and transformed into chemically competent E.coli TOP10 (Invitrogen). MSP was performed with primers specific for methylated 
and unmethylated bisulfite converted DNA in the same region as the bisufite sequencing primers. The primers were 5'-TAG TCG CGT TTT TAA ATA TTA TCG A-3' (M-fwd) 5'-CCT AAC CGA CGA AAA ATA ACG-3' (Mrev) and 5'-TAG TTG TGT TTT TAA ATA TTA TTG A3' (U-fwd) 5'-ACC CTA ACC AAC AAA AAA TAA CAC $T-3^{\prime}$ (U-rev). PCR products were analyzed on a $2 \%$ agarose gel.

\section{Demethylation experiments using 5'-Aza-2'deoxycytidine}

To perform demethylation experiments, the ovarian cancer cell line ES-2 that is methylated in the SOX11 promoter was used. ES-2 was seeded and grown $\mathrm{o} / \mathrm{n}$ until $60 \%$ confluency. 5-Aza-dC (Sigma Aldrich, St. Louis, MO, USA) was applied $(2 \mu \mathrm{M}$ or $10 \mu \mathrm{M})$ to the wells together with fresh media every $24^{\text {th }}$ hours. Equivalent amount of media was added to mock-treated cells. After 96 hours the cells were harvested by trypsination. DNA and protein was extracted as above. Quantification of DNA and protein was performed using the volume measurement (Intensity*Area) and global background subtraction in Quantity One software (Bio-Rad). For DNA quantification, the total volume of pairwise DNA samples (treated and untreated control samples) was set to $100 \%$. For protein quantification, the relative volume of untreated control sample was set to 1 .

\section{Overexpression of SOX11 in EOC cell lines}

Transfection of the cells to overexpress SOX11 was performed following the Lipofectamine ${ }^{\mathrm{TM}} 2000$ protocol (Invitrogen). Briefly, one to two days prior to transfection $50000-100000$ cells $/ \mathrm{cm}^{2}$ from each cell line were seeded into culture vessels. Transfection was performed with the SOX11-GFP plasmid, OmicsLink ${ }^{\mathrm{TM}}$ Expression Clone, EXM0425-M46 (GeneCopoeia ${ }^{\mathrm{TM}}$ ), in one culture vessel and with the GFP plasmid; OmicsLink ${ }^{\mathrm{TM}}$ Expression Clone, EX-EGFP-M02 (GeneCopoeia ${ }^{\mathrm{TM}}$ ); in another with a DNA $(\mu \mathrm{g}):$ Lipofectamine ${ }^{\mathrm{TM}} 2000(\mu \mathrm{l})$ ratio of 1:2.5. 24 hours after transfection the cells were harvested and samples were taken for mRNA, protein and proliferation assays.

\section{Proliferation assay using [methyl-3H]-thymidine incorporation and assessment of confluency}

The proliferation assays were performed using [methyl$3 \mathrm{H}$ ]-thymidine incorporation. 15000 cells were seeded in triplicates onto 96-well plates, left for a couple of hours for the cells to attach, then $[3 \mathrm{H}]$-thymidine $(1 \mathrm{mCi} / \mathrm{ml}$, $5 \mathrm{Ci} / \mathrm{mmol}$, Amersham, GE Healthcare) was added and the cells were incubated for 8-16 hours. Cells were then frozen and finally thawed and harvested in a Tomtec Harvester 96 (Tomtec, Hamden, CT, USA) and analysed with a 1450 MICROBETA liquid scintillation counter (Wallac (now PerkinElmer ${ }^{\circledR}$, Waltham, MA, USA)). To assess confluency, treated and control cell lines were photographed
$48 \mathrm{~h}$ after overexpression of SOX11 using a Fluovert FS inverted microscope (Leitz, MI, United States) with $32 \times$ magnification and a Nikon Coolpix 995 digital camera (Nikon, Tokyo, Japan).

\section{Results}

SOX11 expression and correlation to survival in high grade and endometrioid carcinomas

SOX11 was recently discovered to be a diagnostic $[12-14,16]$, prognostic $[15,17]$ and functionally associated antigen [18] in B cell lymphomas, but also of prognostic value in EOC [19]. To further investigate the importance of SOX11 expression in EOC, we used a large TMA comprising different histological variants, such as mucinous, serous, endometrioid and clear cell $[22,28]$. A tumor specific nuclear algorithm (IHC-MARK) was developed and used to evaluate the nuclear SOX11 protein expression. A representative IHC staining showing nuclear expression of SOX11 is shown in Figure 1a. Kaplan Meier estimates demonstrated an association between SOX11 nuclear expression and an improved cancer-specific survival in high grade EOC ( $\mathrm{p}=0.047$ ) (Figure $1 \mathrm{~b})$. Multivariate analysis demonstrated a co-dependence with stage. Analysis of SOX11 expression in relation to histological subtypes revealed a non-significant trend towards an improved overall survival (OS) within the endometrioid subtype ( $\mathrm{p}=$ 0.066) (data not shown)). In contrast to previous data where SOX11 mRNA was shown to specifically be expressed in high grade serous cancer [11], our analyses showed no correlation between SOX11 status and distribution of high and low grade tumours in individual histological subtypes (data not shown).

\section{SOX11 promoter methylation status correlates to mRNA and protein expression}

In an attempt to understand the functional implications of SOX11 expression in EOC, we analysed the expression of both SOX11 mRNA and protein in five different EOC cell lines. TOV-112D and OVCAR-3 were shown to have significant levels of SOX11 expression (Figure 2) as compared to the other cell lines. Of interest, TOV-112D is of endometrioid origin and the expression of SOX11 in this cell line is consistent with the presence of primary SOX11-positive endometrioid tumours (Table 1). The origin of OVCAR-3, which also expressed SOX11, is unfortunately not known. To determine the methylation status of the SOX11 promoter in all five EOC cell lines sodium bisulfite sequencing was used. $28 \mathrm{CpG}$ 's in the SOX11 promoter were analysed (Table 3 ) and the percentage of methylated CpG's calculated (Figure 2). The three cell lines A2780, A2780-CP7 and ES-2 were highly methylated which correlated with a complete lack of SOX11 expression at both mRNA and protein level. The two cell lines TOV-112D and OVCAR-3, on the other hand, were 


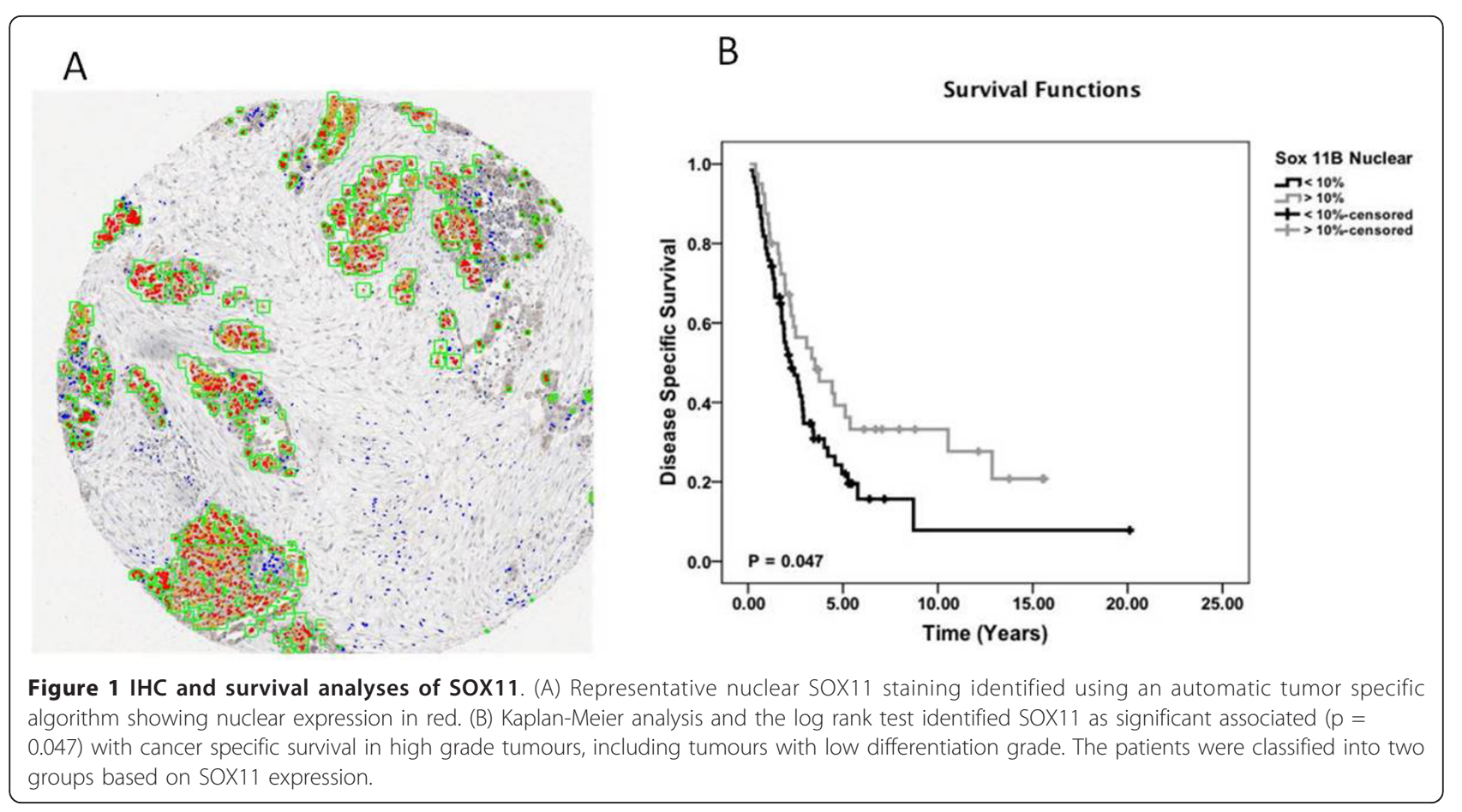

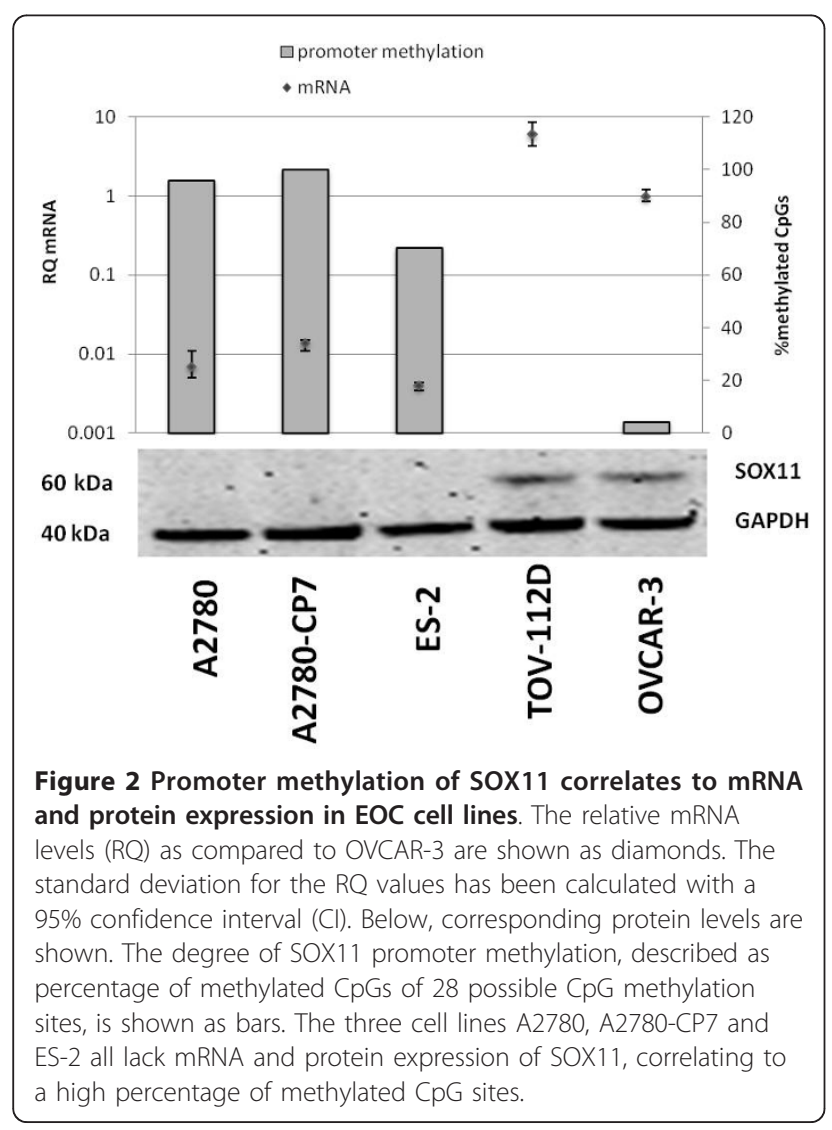

demethylated in the SOX11 promoter, which correlated to expression of SOX11 at both the mRNA and protein level.

\section{Demethylation of ovarian cancer cell line ES-2 induced SOX11 mRNA and protein expression}

The SOX11 negative epithelial ovarian cancer cell line ES-2 is methylated in the SOX11 promoter region. In order to demonstrate that the methylation is responsible for silencing of the SOX11 gene, this cell line was treated with the demethylating agent 5-Aza-dC. Treatment of ES-2 with 2 and $10 \mu \mathrm{M} 5$-Aza-dC for 96 hours resulted in demethylation of the SOX11 promoter (Figure 3A). Quantification showed an increase from $8 \%$ (untreated control) to $57 \%(2 \mu \mathrm{M} 5$-Aza-dC) and $82 \%$ $(2 \mu$ M 5-Aza-dC) unmethylated DNA. This was accompanied by an immediate upregulation of SOX11 mRNA (Figure 3B). Also analysis on the protein level confirmed expression of SOX11 and quantification showed a 4.6 and 3.5 fold increase in protein level comparing treated ( 2 and $10 \mu \mathrm{M} 5$-Aza-dC, respectively) with untreated samples (Figure 3C). Analysis of the absolute levels of SOX11 in wt SOX11-positive and negative EOC cell lines showed that TOV-112D and OVCAR-3 had a $\Delta \mathrm{C}_{\mathrm{T}}$, sox11 of 5.4 and 7.0 respectively, while $\Delta \mathrm{C}_{\mathrm{T}, \mathrm{SOX} 11}$ were $<1.0$ for the negative cell lines. Thus, it is clear that the demethylation resulted in significant amounts of SOX11, but at a level lower than the wt positive cell lines. Thus, SOX11-negative ovarian cancer cell lines are specifically 
Table 3 Methylation status of individual CpGs in EOC cell lines

\begin{tabular}{|c|c|c|c|c|c|}
\hline Cog position & A2780 & A2780-CP7 & ES-2 & TOV-112D & OVCAR-3 \\
\hline CpG1 & $\mathrm{NA}^{1}$ & NA & UM & UM & NA \\
\hline CpG2 & NA & NA & NA & UM & NA \\
\hline CpG3 & $\mathbf{M}^{2}$ & NA & UM & UM & NA \\
\hline CpG4 & $\mathrm{UM}^{3}$ & NA & UM & UM & NA \\
\hline CpG5 & M & $M$ & $M$ & UM & $M$ \\
\hline CpG6 & $M$ & $M$ & $M$ & UM & UM \\
\hline CpG7 & $M$ & M & UM & UM & UM \\
\hline CpG8 & $M$ & M & $M$ & UM & UM \\
\hline CpG9 & $M$ & $M$ & UM & UM & UM \\
\hline CpG10 & M & $M$ & $M$ & UM & UM \\
\hline CpG11 & $M$ & $M$ & UM & UM & UM \\
\hline CpG12 & $M$ & M & UM & UM & UM \\
\hline CpG13 & M & M & M & UM & UM \\
\hline CpG14 & $M$ & $M$ & M & UM & UM \\
\hline CpG15 & $M$ & M & UM & UM & UM \\
\hline CpG16 & $M$ & $M$ & $M$ & UM & UM \\
\hline CpG17 & $M$ & $M$ & $M$ & UM & UM \\
\hline CpG18 & M & NA & $M$ & UM & UM \\
\hline CpG19 & NA & $M$ & $M$ & UM & UM \\
\hline CpG20 & $M$ & $M$ & $M$ & UM & UM \\
\hline CpG21 & $M$ & $M$ & $M$ & UM & UM \\
\hline CpG22 & $M$ & $M$ & $M$ & UM & UM \\
\hline CpG23 & $M$ & $M$ & $M$ & UM & UM \\
\hline CpG24 & $M$ & $M$ & $M$ & UM & UM \\
\hline CpG25 & $M$ & $M$ & $M$ & UM & UM \\
\hline CpG26 & $M$ & $M$ & $M$ & UM & UM \\
\hline CpG27 & $M$ & $M$ & $M$ & UM & UM \\
\hline CpG28 & $M$ & $M$ & $M$ & UM & UM \\
\hline
\end{tabular}

${ }^{1} \mathrm{NA}$ - sequence data not available.

${ }^{2} \mathrm{M}$ - methylated $\mathrm{CpG}$ positions are shown in bold.

${ }^{3} \mathrm{UN}$ - unmethylated CpG positions.

silenced by DNA methylation that at least partly can be reversed by demethylating drugs.

\section{Overexpression of SOX11 in EOC cell lines}

To further evaluate the functional role of SOX11 the gene was overexpressed in five different EOC cell lines, by transfecting them with a SOX11-GFP plasmid (OmicsLink $^{\mathrm{TM}}$ Expression Clone). Transfection efficiency was 40-90\%, measured as GFP positive control cells in flow cytometry (data not shown). Both mRNA and protein extracts were analysed by qRT-PCR and western blot to confirm an overexpression of SOX11. Furthermore, the proliferation of the cells was assessed by thymidine incorporation. The level of overexpression at mRNA level varied between a 100-fold (A2780) to a 50000-fold (A2780-CP7). For most cell lines the increase in mRNA was also translated into an overexpression of the SOX11 protein. However, the 1000-fold increase of mRNA in OVCAR-3 only resulted in a limited increase of SOX11 protein (Figure 4A). Using light microscopy to investigate the confluency of the cell lines, it was evident that the induction of SOX11 overexpression resulted in a significant decrease in cell number (Figure 4B), as compared to the control. Furthermore, the overexpression of SOX11 resulted in a decrease in proliferation in all cell lines (Figure 4C). There was not a linear correlation between level of overexpression and reduction in cell proliferation. Among others, OVCAR-3, with a modest increase of SOX11 protein responded with $>50 \%$ reduced proliferation, while A2780-CP7, with the strongest overexpression showed a lower decrease in growth rate. The difference in response to SOX11 overexpression comparing different cell lines may be related to the need of co-factors, as the strongest effect was seen in cell lines which already expressed SOX11, as also has been reported for B cell lymphomas [18].

\section{Discussion}

SOX11 has previously been identified as a prognostic antigen in EOC, where SOX11 expression was associated with a prolonged recurrence free survival [19]. In this study, we demonstrated that SOX11 was associated with an improved survival among patients with high-grade carcinomas and potentially also with endometrioid carcinomas, although the latter needs to be statistically confirmed in a larger cohort of patients. It is well known that EOC constitutes a diverse set of malignancies, each with a separate histology, gene expression pattern [29] and outcome tightly linked to the underlying biology [4]. It has been shown that low malignant potential tumours often progress to low grade serous carcinomas but that high grade tumours rapidly develop from surface epithelium without evidence of previous lesion [30]. This is consistent with a stepwise mutation process (low-grade pathway) or a greater genetic instability (high-grade pathway), as previously reviewed [31]. It is of major interest that SOX11 can be used to further subdivide high grade tumours, which also indicates a functional role for SOX11 as a tumour suppressor. It is not clear whether SOX11 defines endometrioid carcinoma of a specific origin, since it has been suggested that they, like clear cell ovarian cancer, may be derived from endometriotic deposits in contrast to the surface epithelial layer of the ovary or distal fallopian tube [32]. Of importance, SOX11 is expressed in early progenitor human multipotent stromal cells but expression decreases with expansion of the cells [33]. Further studies are needed to determine if SOX11 also is associated with differentiation pattern in endometrioid carcinomas, although they are known to mostly be well differentiated [34], in contrast to our cohort. Preliminary, no association with differentiation grade of endometrioid carcinomas and SOX11 expression was seen, although the number of patients was limited. More apparent, SOX11 expression 
A

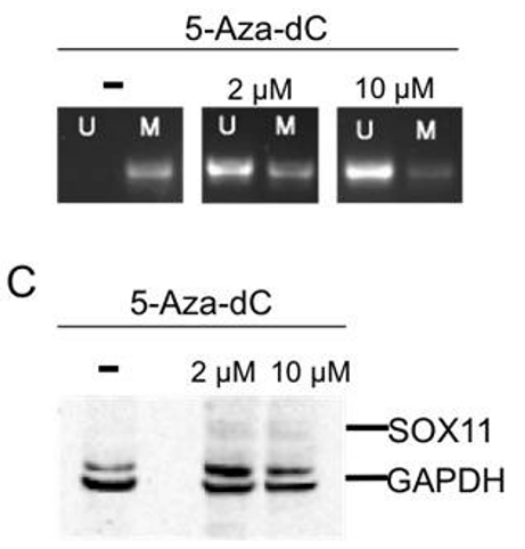

B

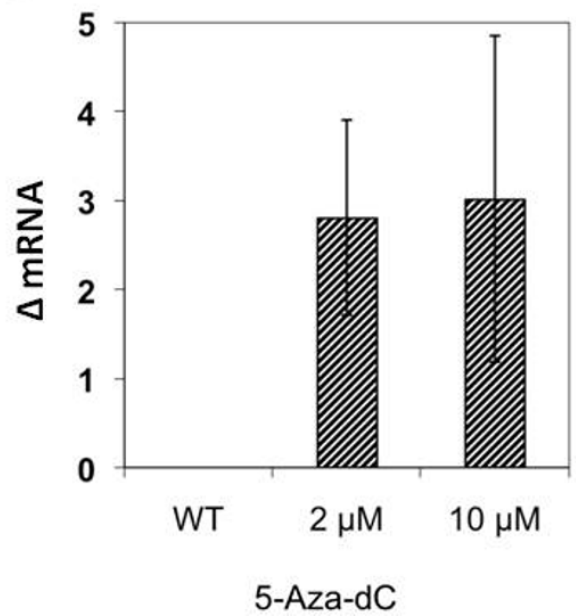

Figure 3 Induced expression of SOX11 in ES-2. (A) Treatment of the ovarian cancer cell line ES-2 with 5-Aza-dC for 96 h led to demethylation of the SOX11 promoter. (B) SOX11 mRNA can be detected above background level by qRT-PCR. (C) SOX11 protein expression as determined by Western Blot analysis. The data shown here is a representative example of three independent experiments.

was not restricted to a specific histological subtype, however most SOX11 positive cases were found in the serous and endometrioid subtypes. Correlation to the in vitro models could not be performed as the majority of these are poorly characterized. Some of the cell lines we used have previously been xenografted into nude mice to analyse the resulting pathologies [27], but no firm conclusion can be drawn between any correlation of SOX11 and their potential histological subtype.

As previously shown for B cell lymphoma cell lines [18], the protein and mRNA expression of SOX11 in ovarian cancer cell lines correlated with the methylation status of the SOX11 promoter region. Given the tumour suppressor function of SOX11 [18] and the association with cell cycle status [35], which has been demonstrated previously by us in lymphomas, it is not surprising that the promoter region of SOX11 in some EOC cell lines becomes methylated in order to silence gene expression. In ovarian cancer cell lines, knock-down of DNMT1 and DNMT3b, resulting in loss of CpG hypermethylation, has a negative effect on growth [36]. The specific methylation of tumour suppressors is a known event in many different cancers and is commonly studied by forced demethylation through agents such as 5-Aza-dC, that inhibit the DNA methyl transferases (DNMT's) $[37,38]$ and subsequent analysis of expression of target genes. Here, we were able to demethylate the SOX11 promoter in the ovarian cancer cell line ES-2, resulting in a successful expression of SOX11 mRNA and protein. However, the level of SOX11 expression upon demethylation was significantly lower compared to SOX11 wt positive control cell lines such as TOV-112D and OVCAR-3. Probably, there are additional epigenetic factors besides an unmethylated promoter that are needed to reach the endogenous levels of wt SOX11 expression. Others have recently shown that SAHA treatment used in combination with 5-Aza-dC increase the expression of SOX11 in a negative B cell lymphoma cell line [39]. In ovarian cancer, platinum-resistance is a common problem and it has been proposed that this might in part be explained by hypermethylation and other epigenetic events that repress tumour suppressor genes in general [40]. Thus, the successful use of DNMT and HDAC (Histone deacetylases) inhibitors for chemotherapy re-sensitization in ovarian cancer cell lines and animal models imply that epigenetic therapies could be a future method for clinical chemo re-sensitization [40]. This is also supported by our data where forced SOX11 expression leads to a reduced proliferation.

Of interest, the clinical outcome of patients afflicted by EOC has been associated to differential expression of cell cycle regulatory proteins including Cyclin D1, Cyclin E, p16-INK and E2F transcription factors [41]. We have previously shown that some of these proteins, including p16INK, Rb and E2F transcription factors [18] change their expression, as a result of overexpression of SOX11 in lymphoma cell lines and these genes may thus be responsible for the improved survival associated with SOX11-positive tumours also in EOC.

\section{Conclusions}

In the present study, SOX11 was demonstrated to be of prognostic value for high grade EOC, which could have a clear clinical value. The possibility to re-express 


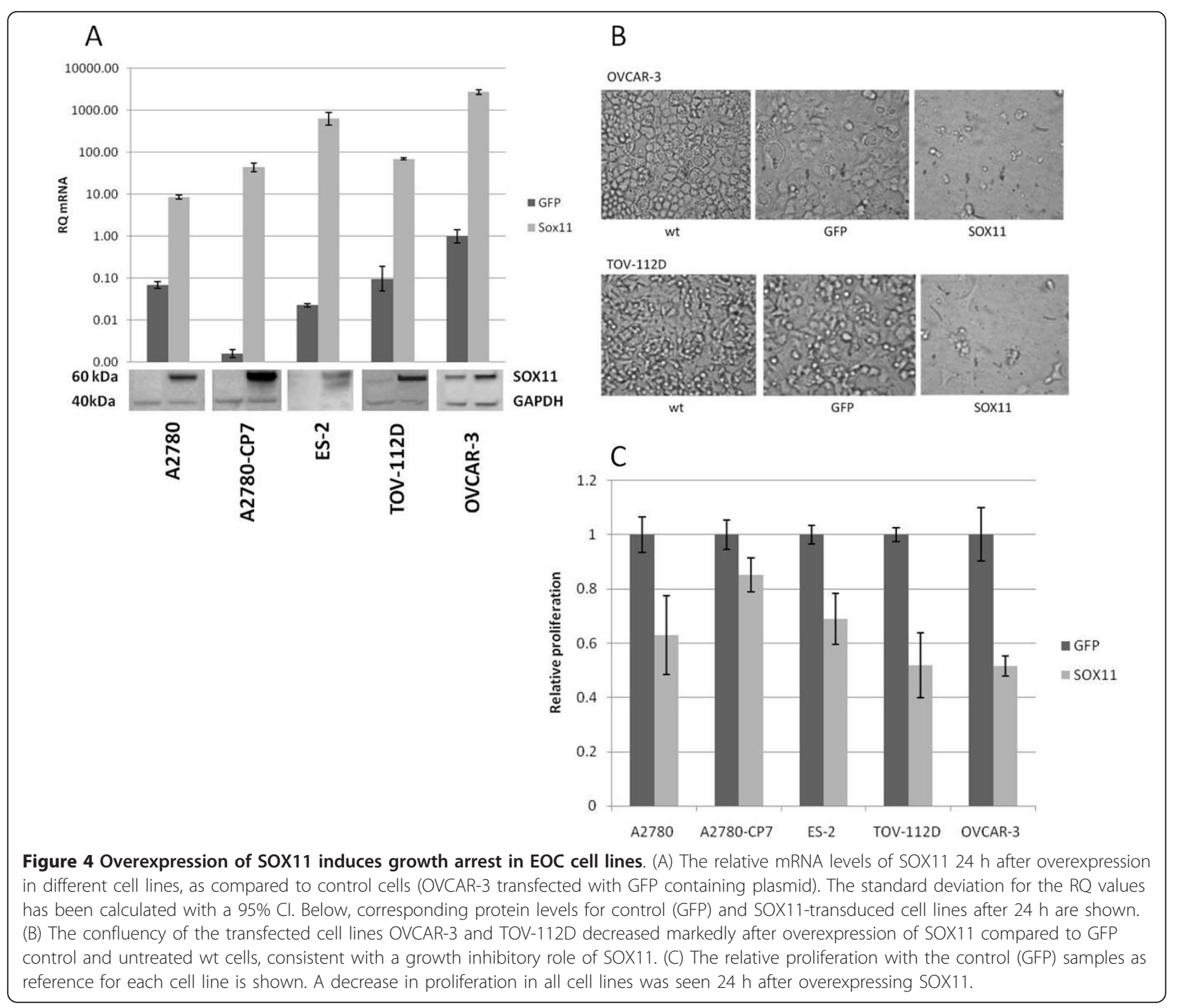

SOX11 indicates a potential use of epigenetic drugs to affect cell growth through common cell regulatory pathways, controlled by SOX11, and other tumour suppressors that are silenced in EOC. Furthermore, functional investigations in vitro confirmed a growth regulatory role for SOX11 in EOC.

\section{Acknowledgements}

The study was supported by Lund University, Lund Institute of Technology $(\mathrm{LTH})$, Bioinvent International AB, the Leukemia and Lymphoma Society (Grant No. R6189-09), Cancerfonden (08-0285), Smärtafonden (SSF/09-05) and CREATE Health, a Strategic Center for Translational Cancer Research http:// www.createhealth.lth.se. The UCD Conway Institute is funded by the Programme for Third Level Institutions (PRTLI), as administered by the Higher Education Authority (HEA) of Ireland. Funding is acknowledged from Enterprise Ireland (WG, DB and ER).

\section{Author details}

'Department of Immunotechnology, Lund University, Lund, Sweden. ${ }^{2}$ CREATE Health, Lund University, BMC D13, 22184 Lund, Sweden. ${ }^{3}$ UCD
School of Biomolecular and Biomedical Science, UCD Conway Institute, University College, Dublin, Ireland. ${ }^{4}$ Department of Clinical Sciences, Pathology, Lund University Hospital, Lund University, Lund, Sweden.

\section{Authors' contributions}

SS performed experimental work, including overexpression studies, analysis of the cell lines and took active part in writing the manuscript. EG performed experimental work in relation to promoter methylation analysis and took active part in writing the manuscript. DJB was responsible for the design of the automated SOX11 classification, interpretation of the data and involved in the completion of the manuscript. WMG and ER were involved in the design of the algorithm for automated IHC classification. FR performed experimental work in relation to overexpression of SOX $11 . \mathrm{KJ}$ provided the tumour material and clinical data and was involved in the completion of the manuscript. CB was involved in the design of the study and the completion of the manuscript. SE was responsible for the design of the study, interpretation of data and writing of the manuscript. All authors read and approved the final manuscript.

\section{Competing interests}

A patent has been filed on the use of SOX11 as a diagnostic and prognostic antigen in EOC. 
Received: 23 June 2011 Accepted: 24 September 2011

Published: 24 September 2011

\section{References}

1. Gilks CB, lonescu DN, Kalloger SE, Kobel M, Irving J, Clarke B, Santos J, Le N, Moravan $V$, Swenerton K: Tumor cell type can be reproducibly diagnosed and is of independent prognostic significance in patients with maximally debulked ovarian carcinoma. Human pathology 2008 39:1239-1251.

2. Silverberg SG: Prognostic significance of pathologic features of ovarian carcinoma. Current topics in pathology 1989, 78:85-109.

3. Mackay HJ, Brady MF, Oza AM, Reuss A, Pujade-Lauraine E, Swart AM, Siddiqui N, Colombo N, Bookman MA, Pfisterer J, du Bois A: Prognostic relevance of uncommon ovarian histology in women with stage III/IV epithelial ovarian cancer. Int J Gynecol Cancer 2010, 20:945-952.

4. Berchuck A, Iversen ES, Luo J, Clarke JP, Horne H, Levine DA, Boyd J, Alonso MA, Secord AA, Bernardini MQ, et al: Microarray analysis of early stage serous ovarian cancers shows profiles predictive of favorable outcome. Clin Cancer Res 2009, 15:2448-2455.

5. Kobel M, Kalloger SE, Boyd N, McKinney S, Mehl E, Palmer C, Leung S, Bowen NJ, lonescu DN, Rajput A, et al: Ovarian carcinoma subtypes are different diseases: implications for biomarker studies. PLOS medicine 2008, 5:e232.

6. Takano M, Kikuchi Y, Yaegashi N, Kuzuya K, Ueki M, Tsuda H, Suzuki M, Kigawa J, Takeuchi S, Tsuda H, et al: Clear cell carcinoma of the ovary: a retrospective multicentre experience of 254 patients with complete surgical staging. British journal of cancer 2006, 94:1369-1374.

7. Fader AN, Rose PG: Role of surgery in ovarian carcinoma. J Clin Oncol 2007, 25:2873-2883.

8. Hennessy BT, Coleman RL, Markman M: Ovarian cancer. Lancet 2009, 374:1371-1382

9. Schwartz DR, Kardia SL, Shedden KA, Kuick R, Michailidis G, Taylor JM, Misek DE, Wu R, Zhai Y, Darrah DM, et al: Gene expression in ovarian cancer reflects both morphology and biological behavior, distinguishing clear cell from other poor-prognosis ovarian carcinomas. Cancer research 2002, 62:4722-4729.

10. Zorn KK, Bonome T, Gangi L, Chandramouli GV, Awtrey CS, Gardner GJ, Barrett JC, Boyd J, Birrer MJ: Gene expression profiles of serous, endometrioid, and clear cell subtypes of ovarian and endometrial cancer. Clin Cancer Res 2005, 11:6422-6430.

11. Tothill RW, Tinker AV, George J, Brown R, Fox SB, Lade S, Johnson DS, Trivett MK, Etemadmoghadam D, Locandro B, et al: Novel molecular subtypes of serous and endometrioid ovarian cancer linked to clinical outcome. Clin Cancer Res 2008, 14:5198-5208.

12. Chen $\mathrm{YH}$, Gao J, Fan G, Peterson LC: Nuclear expression of sox 11 is highly associated with mantle cell lymphoma but is independent of $t(11 ; 14)(q 13$; q32) in non-mantle cell B-cell neoplasms. Mod Pathol 2010, 23:105-112.

13. Dictor M, Ek S, Sundberg M, Warenholt J, Gyorgy C, Sernbo S, Gustavsson E, Abu-Alsoud W, Wadstrom T, Borrebaeck C: Strong lymphoid nuclear expression of SOX11 transcription factor defines lymphoblastic neoplasms, mantle cell lymphoma and Burkitt's lymphoma. Haematologica 2009, 94:1563-1568.

14. Ek S, Dictor M, Jerkeman M, Jirstrom K, Borrebaeck CA: Nuclear expression of the non B-cell lineage Sox11 transcription factor identifies mantle cell lymphoma. Blood 2008, 111:800-805.

15. Fernandez V, Salamero O, Espinet B, Sole F, Royo C, Navarro A, Camacho F, Bea S, Hartmann E, Amador $V$, et al: Genomic and gene expression profiling defines indolent forms of mantle cell lymphoma. Cancer research 2010, 70:1408-1418.

16. Mozos A, Royo C, Hartmann E, De Jong D, Baro C, Valera A, Fu K, Weisenburger DD, Delabie J, Chuang SS, et al: SOX11 expression is highly specific for mantle cell lymphoma and identifies the cyclin D1-negative subtype. Haematologica 2009, 94:1555-1562.

17. Wang $X$, Asplund AC, Porwit A, Flygare J, Smith Cl, Christensson B, Sander B: The subcellular Sox11 distribution pattern identifies subsets of mantle cell lymphoma: correlation to overall survival. British journal of haematology 2008, 143:248-252.

18. Gustavsson E, Sernbo S, Andersson E, Brennan DJ, Dictor M, Jerkeman M, Borrebaeck CA, Ek S: SOX11 expression correlates to promoter methylation and regulates tumor growth in hematopoietic malignancies. Molecular cancer 2010, 9:187.
19. Brennan DJ, Ek S, Doyle E, Drew T, Foley M, Flannelly G, O'Connor DP, Gallagher WM, Kilpinen S, Kallioniemi OP, et al: The transcription factor Sox11 is a prognostic factor for improved recurrence-free survival in epithelial ovarian cancer. Eur J Cancer 2009, 45:1510-1517.

20. Berglund G, Elmstahl S, Janzon L, Larsson SA: The Malmo Diet and Cancer Study. Design and feasibility. Journal of internal medicine 1993, 233:45-51.

21. Berglund G, Eriksson KF, Israelsson B, Kjellstrom T, Lindgarde F, Mattiasson I, Nilsson JA, Stavenow L: Cardiovascular risk groups and mortality in an urban swedish male population: the Malmo Preventive Project. Journal of internal medicine 1996, 239:489-497.

22. Ehlen A, Brennan DJ, Nodin B, O'Connor DP, Eberhard J, AlvaradoKristensson M, Jeffrey IB, Manjer J, Brandstedt J, Uhlen M, et al: Expression of the RNA-binding protein RBM3 is associated with a favourable prognosis and cisplatin sensitivity in epithelial ovarian cancer. Journal of translational medicine 2010, 8:78.

23. Rexhepaj E, Brennan DJ, Holloway P, Kay EW, McCann AH, Landberg G, Duffy MJ, Jirstrom K, Gallagher WM: Novel image analysis approach for quantifying expression of nuclear proteins assessed by immunohistochemistry: application to measurement of oestrogen and progesterone receptor levels in breast cancer. Breast Cancer Res 2008, 10: R89.

24. Manning AP, Mes-Masson AM, Seymour RJ, Tetrault M, Provencher DM, Tonin PN: Expression of FHIT in primary cultures of human epithelial ovarian tumors and malignant ovarian ascites. Molecular carcinogenesis 1999, 24:218-225.

25. Hamilton TC, Young RC, McKoy WM, Grotzinger KR, Green JA, Chu EW, Whang-Peng J, Rogan AM, Green WR, Ozols RF: Characterization of a human ovarian carcinoma cell line (NIH:OVCAR-3) with androgen and estrogen receptors. Cancer research 1983, 43:5379-5389.

26. Lau DH, Ross KL, Sikic Bl: Paradoxical increase in DNA cross-linking in a human ovarian carcinoma cell line resistant to cyanomorpholino doxorubicin. Cancer research 1990, 50:4056-4060.

27. Shaw TJ, Senterman MK, Dawson K, Crane CA, Vanderhyden BC: Characterization of intraperitoneal, orthotopic, and metastatic xenograft models of human ovarian cancer. Mol Ther 2004, 10:1032-1042.

28. Nodin B, Zendehrokh N, Brandstedt J, Nilsson E, Manjer J, Brennan DJ, Jirstrom K: Increased androgen receptor expression in serous carcinoma of the ovary is associated with an improved survival. J Ovarian Res 2010, $3: 14$.

29. Gomez-Raposo C, Mendiola M, Barriuso J, Hardisson D, Redondo A: Molecular characterization of ovarian cancer by gene-expression profiling. Gynecologic oncology 2010, 118:88-92.

30. Bell DA, Scully RE: Early de novo ovarian carcinoma. A study of fourteen cases. Cancer 1994, 73:1859-1864

31. Landen CN Jr, Birrer MJ, Sood AK: Early events in the pathogenesis of epithelial ovarian cancer. J Clin Oncol 2008, 26:995-1005.

32. Feeley KM, Wells M: Precursor lesions of ovarian epithelial malignancy. Histopathology 2001, 38:87-95.

33. Larson BL, Ylostalo J, Lee RH, Gregory C, Prockop DJ: Sox 11 is expressed in early progenitor human multipotent stromal cells and decreases with extensive expansion of the cells. Tissue engineering 2010, 16:3385-3394.

34. Kurman RJ, McConnell TG: Precursors of endometrial and ovarian carcinoma. Virchows Arch 2010, 456:1-12.

35. Conrotto P, Andreasson U, Kuci V, Borrebaeck CA, Ek S: Knock-down of SOX11 induces autotaxin-dependent increase in proliferation in vitro and more aggressive tumors in vivo. Mol Oncol 2011.

36. Leu YW, Rahmatpanah F, Shi H, Wei SH, Liu JC, Yan PS, Huang TH: Double RNA interference of DNMT3b and DNMT1 enhances DNA demethylation and gene reactivation. Cancer research 2003, 63:6110-6115.

37. Bender CM, Pao MM, Jones PA: Inhibition of DNA methylation by 5-aza2 '-deoxycytidine suppresses the growth of human tumor cell lines. Cancer research 1998, 58:95-101.

38. Christman JK: 5-Azacytidine and 5-aza-2'-deoxycytidine as inhibitors of DNA methylation: mechanistic studies and their implications for cancer therapy. Oncogene 2002, 21:5483-5495.

39. Vegliante MC, Royo C, Palomero J, Salaverria I, Balint B, Martin-Guerrero I, Agirre X, Lujambio A, Richter J, Xargay-Torrent S, et al: Epigenetic activation of SOX11 in lymphoid neoplasms by histone modifications. PLoS One 2011, 6:e21382.

40. Matei DE, Nephew KP: Epigenetic therapies for chemoresensitization of epithelial ovarian cancer. Gynecologic oncology 2010, 116:195-201. 
41. Gadducci A, Cosio S, Tana R, Genazzani AR: Serum and tissue biomarkers as predictive and prognostic variables in epithelial ovarian cancer. Critical reviews in oncology/hematology 2009, 69:12-27.

\section{Pre-publication history}

The pre-publication history for this paper can be accessed here: http://www.biomedcentral.com/1471-2407/11/405/prepub

doi:10.1186/1471-2407-11-405

Cite this article as: Sernbo et al:: The tumour suppressor SOX11 is

associated with improved survival among high grade epithelial ovarian cancers and is regulated by reversible promoter methylation. $B M C$

Cancer 2011 11:405.

Submit your next manuscript to BioMed Central and take full advantage of:

- Convenient online submission

- Thorough peer review

- No space constraints or color figure charges

- Immediate publication on acceptance

- Inclusion in PubMed, CAS, Scopus and Google Scholar

- Research which is freely available for redistribution

Submit your manuscript at www.biomedcentral.com/submit 